\title{
OUTCOME OF ACUTE RESPIRATORY DISTRESS SYNDROME NETWORK PROTOCOL IMPLEMENTATION IN PATIENTS WITH ACUTE LUNG INJURY/ACUTE RESPIRATORY DISTRESS SYNDROME.
}

\author{
Ramadan M. Nafae*, Mohamed F. Ismail*, Reda M. Elghamry*, Adel M. Hamada* \\ "Chest Diseases Department, Faculty of Medicine, Zagazig University, Egypt.
}

\begin{abstract}
Background: There is under-use of ARDS Network ventilatory protocol in managing ARDS patients. Hence the objective of this study was to assess the impact of implementing ARDS network protocol, as a ventilatory strategy in management of ALI/ARDS patients.

Design: retrospective-prospective comparative study.

Patients and Methods: This study was conducted on 40 mechanically ventilated patients with ARDS admitted at ICUs of Zagazig University Hospitals. Twenty newly admitted cases of ALI/ARDS (group I)(prospective group) that have been managed by ARDS Network protocol of mechanical ventilation were compared with another 20 patients who have not been managed by ARDS Network protocol of mechanical ventilation (group II) (retrospective group).

Results: Both groups were matched as regards age, sex,smoking habits, oxygenation ratio and SAPS II on admission .There were a significant statistical difference between both groups as regards tidal volume and plateau pressure on days $1,3 \& 7$ with mortality ( $60 \%$ vs. $90 \% \mathrm{p}=0.028)$, duration of MV(18.6 vs. 25.5 days $\mathrm{p}=0.001)$, LOS in ICU among survivors (22.6 vs. 30.5 days $\mathrm{p}=0.001$ ) and barotraumas ( 1 vs. 6 patients $\mathrm{p}=0.037$ ) in group I and group II respectively.

Conclusions: Application of ARDS Network ventilatory protocol as a ventilatory strategy in ARDS patients decreases the overall mortality, days on mechanical ventilation, the length of stay in ICU and the incidence of barotrauma.

Key words: ARDS, mechanical ventilation, low tidal volume, ARDS Network, ICU.
\end{abstract}

\section{INTRODUCTION}

A cute lung injury (ALI) and ARDS involve a heterogeneous process in the lungs that results in diffuse alveolar damage. The current characteristics associated with ALI include bilateral infiltrates on chest radiograph, $\mathrm{PaO} 2$ to $\mathrm{FIO} 2$ ratio less than 300, no evidence of left ventricular failure evidenced by a pulmonary artery occlusive pressure less than $18 \mathrm{~mm} \mathrm{Hg}$ or central venous pressure less than $14 \mathrm{~mm} \mathrm{Hg}$, and need for invasive mechanical ventilator support. ARDS is a subset of patients whose $\mathrm{PaO} 2$ to FIO 2 ratio is less than or equal to $200^{[1]}$.

ALI (or ARDS) is associated with a variety of causative factors, which can be grouped into two general categories: those associated with direct lung injury via the airways and those associated with indirect lung injury via the blood stream ${ }^{[2]}$.

Regardless of whether injury originates within or outside of the lung, the lung injury is associated with a systematic inflammatory response. ${ }^{[1]}$

The only method of mechanical ventilation that has been shown in randomized controlled trials to improve survival in patients with ARDS is low tidal volume ventilation. ${ }^{[3]}$

In the last decade with the emergence of SARS, $\mathrm{H} 5 \mathrm{~N} 1$, and H1N1 pandemic globally, there was an increase in ARDS cases; and consequently the need for positive pressure invasive mechanical ventilation. $^{[2]}$
In spite of using a low tidal volume in ventilation of ARDS cases, it was observed that some intensevists deviates from complete application of ARDS network ventilatory protocol, not taking into consideration $\mathrm{P}$ Plateau and/or PEEP-FIO2 combination to achieve target oxygenation and/or target $\mathrm{PH}$.

In ARMA (Respiratory Management in Acute Lung Injury/ARDS, 2000), ventilation with low tidal volumes and plateau pressures resulted in a nearly $9 \%$ absolute reduction in the risk of death. Therefore, high tidal volumes and high plateau pressures should be avoided in patients with ARDS, and critical care clinicians should utilize low tidal volumes as part of a ventilatory protocol that also limits plateau pressure. Specifically, it is recommended that practitioners utilize the ventilatory protocol outlined by the ARDS Network investigators in an ARMA publication from 2000.

Since the publication of ARMA, low tidal volume ventilation has remained underutilized in the treatment of patients with ARDS. Common barriers to the initiation of low tidal volume ventilation include unwillingness to relinquish control of the ventilator, failure to recognize patients as having ALI/ARDS, and perceived contraindications to low tidal volume ventilation. Significant barriers to the continuation of low tidal volume ventilation include concerns regarding patient discomfort and tachypnea or hypercapnia and acidosis. 


\section{PATIENTS AND METHODS}

The study was carried out at the Intensive Care Units of Chest and Anesthesiology departments, Zagazig University Hospitals in the period from November 2011 to November 2013.

Patients with ALI/ARDS, regardless the cause, have been recruited.

\section{Patients of this study included two groups:}

1. (Group A) ARDS Network clinical trial group(prospective group)( 20 patients): Newly admitted cases of ALI/ARDS, upon them ARDS Network protocol of mechanical ventilation has been conducted aged $49.9 \pm 11.33$ years. They were admitted in the period from November 2011 to November 2013. They were (12) males, and (8) females.

2. (Group B) Non ARDS Network clinical trial control group( retrospective group) ( 20 patients):

Patients with ALI/ARDS, who have not be managed by ARDS Network protocol of mechanical ventilation aged $50 \pm 12.3$ years .Their data were collected from file archives.They were collected from the period of October 2009 to October 2011 they were (10) males, and (10) females.

Inclusion criteria:

1. Patients diagnosed as ALI/ARDS according to The American-European Consensus Conference (AECC) on ARDS in 1994:

ALI defined as respiratory failure of acute onset with a $\mathrm{PaO} 2 / \mathrm{FiO} 2$ ratio of less than $300 \mathrm{~mm} \mathrm{Hg}$ (regardless of the level of positive end-expiratory pressure, PEEP), bilateral infiltrates on frontal chest radiograph not attributable to atelectasis or effusions, and no evidence of left atrial hypertension. ARDS was defined identically except for a lower limiting value of less than $200 \mathrm{~mm} \mathrm{Hg}$ for $\mathrm{PaO} 2 / \mathrm{FiO} 2$.

2. Patients age $>18$ years old.

3. Initiation of the ARDS Network protocol occurred (for prospective group) within 24 hours of meeting consensus conference criteria for ARDS.

Exclusion criteria:

1. Age $<18$ yrs

2. Pregnancy.

3. Acute neurologic disease for which hypercapnia would be contraindicated

4. Severe chronic obstructive or restrictive respiratory disease

5. History of sickle cell disease

6. Lobectomy or pneumonectomy during the current hospitalization.

\section{METHODS}

For Group (I) the followings were done:

- Thorough medical history: History taking from the relative(s).

- Full clinical examination: including both general and local chest examinations.

- Plain Chest radiography (antero-posterior view): on admission, and when required.

- Blood glucose level.

- Complete blood count (White blood cells count, Red blood cells count, Hemoglobin and Platelets).

- Kidney function tests (Serum urea level, creatinine).

○ Liver function tests including SGOT, SGPT, serum bilirubin and serum albumin.

- Prothomobin time (PT), Partial thromboplastin time (PTT).

- Arterial blood gas analysis (ABG): including the followings:

- Serum electrolytes ( $\mathrm{Na}, \mathrm{K} . \mathrm{Ca}, \mathrm{Cl})$.

- Electrocardiography and Echocardiography

- Pulse oximetry, non-invasive and blood pressure, central venous pressure, and urine output.

- Ventilator data tabulation as long the patients stay on mechanical ventilation include; VT (in $\mathrm{mL} / \mathrm{kg}$ PBW), end-inspiratory plateau pressure (Pplat), positive end-expiratory pressure (PEEP), , inspired oxygen fraction (FIO2), total respiratory rate (f), arterial $\mathrm{pH}$, arterial carbon dioxide partial pressure $(\mathrm{PaCO} 2)$, and arterial oxygen partial pressure $(\mathrm{PaO} 2)$.

- Calculation of the Simplified Acute Physiology Score (SAPS) II on the first day of admission. ${ }^{[4]}$

- ARDS Clinical Network Mechanical Ventilation Protocol was applied as the following. ${ }^{[5]}$

- Predicted body weight was calculated as the following:

Males : $=50+2.3$ (Height (inches) -60$)$

Females $:=45.5+2.3$ (Height (inches) -60 )

- VAC mode was chosen as a ventilator mode

- Tidal volume was firstly $8 \mathrm{ml} / \mathrm{kg}$ PBW and this was reduced by $1 \mathrm{ml} / \mathrm{kg}$ at intervals $\leq 2$ hours until Vt became $6 \mathrm{ml} / \mathrm{kg}$ PBW

- Initial rate was set to approximate baseline minute ventilation( not exceeding $35 \mathrm{~b} / \mathrm{m}$

- $\quad$ VT \& RR were adjusted to achieve a target PH \& Pplat goals

- Oxygenation goal : Pao2 (55 -80 mmHg) or SPO2 $(88-95 \%)$ by applying incremental FIO2 /PEEP combination using a minimum PEEP of $5 \mathrm{CmH} 2 \mathrm{o}$

- Pplat goal: $(\leq 30 \mathrm{CmH} 2 \mathrm{o})$.

Check Pplat (.5 sec inspiratory pause), at least every $4 \mathrm{hs}$ and after each change of PEEP or Vt. 
If Pplat > $30 \mathrm{Cm} \mathrm{H20:} \mathrm{Vt} \mathrm{was} \mathrm{decreased} \mathrm{by} 1$ $\mathrm{ml} / \mathrm{kg}$ steps (minimum $\mathrm{Vt} 4 \mathrm{ml} / \mathrm{kg}$ ).

If Pplat $<25 \mathrm{Cm} \mathrm{H} 2 \mathrm{o}$ and $\mathrm{Vt}$ is $<6 \mathrm{ml} / \mathrm{kg}$, Vt was increased until Pplat $>25 \mathrm{Cm} \mathrm{H} 2 \mathrm{o}$ or $\mathrm{Vt}=6 \mathrm{ml} / \mathrm{kg}$. If Pplat $<30 \mathrm{cmH} 2 \mathrm{o}$ and breath stacking or dyssynchrony occurs: Vt may be increased in $1 \mathrm{ml} / \mathrm{kg}$ increment to $70 \mathrm{r} 8 \mathrm{ml} / \mathrm{kg}$ provided Pplat $\leq 30 \mathrm{Cm}$ $\mathrm{H} 2 \mathrm{O}$

- pH GOAL: 7.30-7.45

Acidosis Management: $(\mathrm{pH}<7.30)$

If $\mathrm{pH}$ 7.15-7.30: Increase $\mathrm{RR}$ until $\mathrm{pH}>7.30$ or $\mathrm{PaCO} 2<25 \quad$ (Maximum set $\mathrm{RR}=35$ ). If $\mathrm{pH}<$ 7.15: Increase RR to 35.

If $\mathrm{pH}$ remains $<7.15$, VT may be increased in 1 $\mathrm{ml} / \mathrm{kg}$ steps until $\mathrm{pH}>7.15$ (Pplat target of 30 may be exceeded).

May give $\mathrm{NaHCO} 3$

Alkalosis Management: $(\mathrm{pH}>7.45)$ Decrease vent rate if possible.

- I: E RATIO GOAL: Recommend that duration of inspiration be $<$ duration of expiration.

- WEANING

A. Conduct a SPONTANEOUS BREATHING TRIAL daily when:

1. $\mathrm{FiO} 2 \leq 0.40$ and $\mathrm{PEEP} \leq 8 \mathrm{OR} \mathrm{FiO} 2<0.50$ and PEEP $<5$.

2. PEEP and $\mathrm{FiO} 2 \leq$ values of previous day.

3. Patient has acceptable spontaneous breathing efforts. (May decrease vent rate by $50 \%$ for 5 minutes to detect effort.)

4. Systolic $\mathrm{BP} \geq 90 \mathrm{mmHg}$ without vasopressor support.

5. No neuromuscular blocking agents or blockade.

B-SPONTANEOUS BREATHING TRIAL (SBT):

If all above criteria are met and subject has been in the study for at least 12 hours, initiate a trial of UP TO 120 minutes of spontaneous breathing with $\mathrm{FiO} 2<0.5$ and PEEP $<5$ :
1. Place on T-piece, or CPAP $\leq 5 \mathrm{~cm} \mathrm{H} 2 \mathrm{O}$ with PS $<5$

2. Assess for tolerance as below for up to two hours.

a. $\mathrm{SpO} 2 \geq 90$ : and/or $\mathrm{PaO} 2 \geq 60 \mathrm{mmHg}$

b. Spontaneous VT $\geq 4 \mathrm{ml} / \mathrm{kg}$ PBW

c. $\mathrm{RR} \leq 35 / \mathrm{min}$

d. $\mathrm{pH} \geq 7.3$

e. No respiratory distress (distress $=2$ or more)

$\checkmark$ HR $>120 \%$ of baseline

Marked accessory muscle use

Abdominal paradox

Diaphoresis

Marked dyspnea

3. If tolerated for at least 30 minutes, consider extubation.

4. If not tolerated resume pre-weaning settings.

For Group (II) the followings were done:

Data that have been gathered from file achieves included:

as in group I in addition to :

NON ARDS Clinical Network Mechanical Ventilation Protocol was observed : in which low tidal volume (inspite of being not as low as that of group A) was applied and /or there were a deviation from ARDS Clinical Network Mechanical Ventilation Protocol in the form of non respect of plateau pressure values, target oxygenation, target FIO2 \&PEEP.

Comparing outcome in both groups as regard:

- Survival at day $28 .^{[6],[7]}$

- Days on mechanical ventilation . ${ }^{[6],[7]}$

- Lengths of ICU stay. ${ }^{[6],[7]}$

Statistical analysis: Statistical analysis was performed with SPSS version19 software package (SPSS, Inc.Chicago). P value $<0.05$ was considered significant.

\section{RESULTS}

(Table-1): Demographic characteristics of the studied groups $(n=40)$

\begin{tabular}{lllll}
\hline Group & & I(20) & II(20) & P \\
\hline Age & & $49.9 \pm 11.33$ & $50 \pm 12.3$ & 0.83 \\
\hline gender & male & $12(60 \%)$ & $10(50 \%)$ & 0.52 \\
\cline { 2 - 4 } & Female & $8(40 \%)$ & $10(50 \%)$ & \\
\hline \multirow{2}{*}{ smoking } & yes & $7(35 \%)$ & $6(30 \%)$ & 0.73 \\
\cline { 2 - 4 } & no & $13(65 \%)$ & $14(70 \%)$ & \\
\hline
\end{tabular}

This table shows the characteristics of the studied (50 \pm 12.3 years )in group $1 \& 2$ respectively $.60 \%$ patients. Mean age was $(49.9 \pm 11.33$ years $) \mathrm{Vs}$ of patients were males , $40 \%$ were females in group 
1 while in group $2,50 \%$ were males \& $50 \%$ were females .The percentage of smokers was $35 \%$ in (Table -2): Risk factors of ARDS in the studied patients

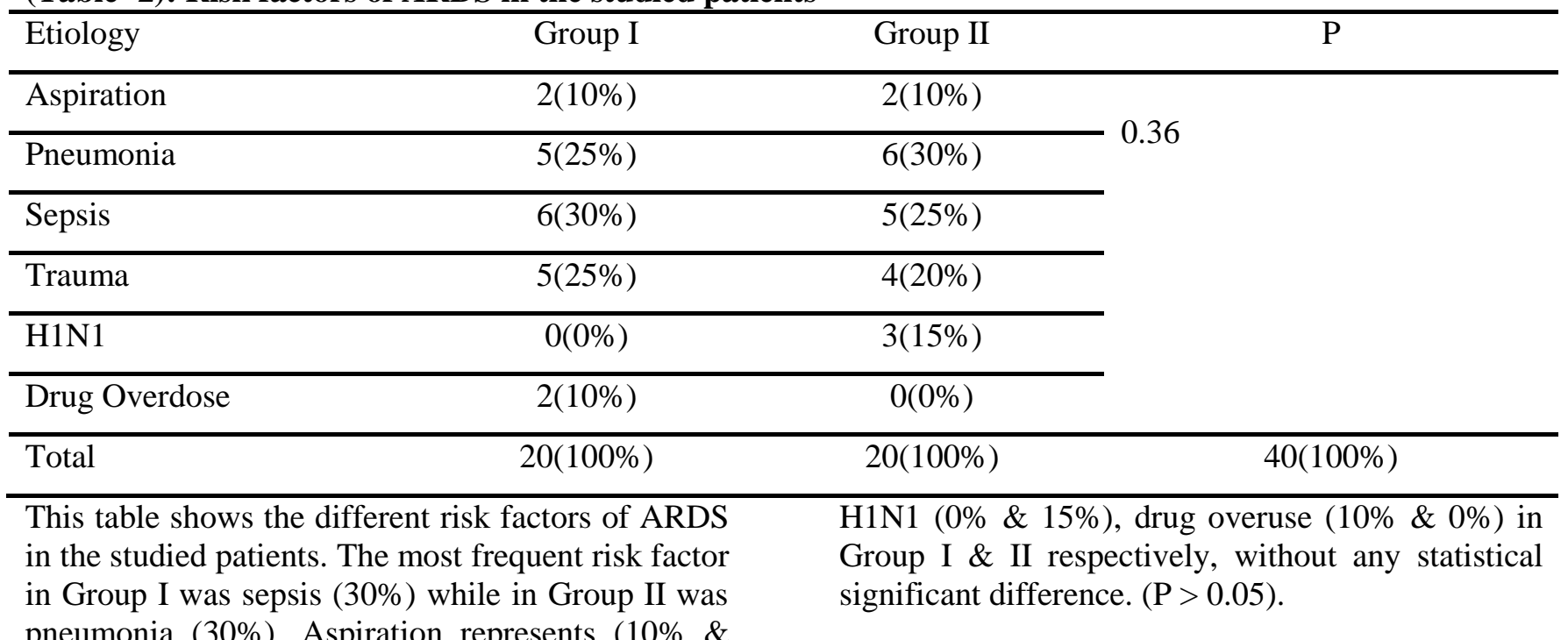

This table shows the different risk factors of ARDS in the studied patients. The most frequent risk factor in Group I was sepsis (30\%) while in Group II was pneumonia (30\%). Aspiration represents $(10 \%$ \& $10 \%)$, pneumonia represents $(25 \% \& 30 \%)$, trauma $(25 \%$ \& $20 \%)$, group $1 \& 30 \%$ in group 2 without any statistical significant difference.$(\mathrm{P}>0.05)$.

(Table-3): $\mathrm{Pao}_{2} / \mathrm{FIO}_{2} \&$ SAPS II in the studied patients on admission.

\begin{tabular}{lccc}
\hline Group & $\mathrm{I}$ & $\mathrm{II}$ & $\mathrm{P}$ \\
\hline $\mathrm{PaO}_{2} / \mathrm{FIo}_{2}$ ratio & $131 \pm 33$ & $118 \pm 29$ & 0.2 \\
\hline SAPS II & $41.7 \pm 3.89$ & $39.3 \pm 5.25$ & 0.1 \\
\hline
\end{tabular}

This table shows that the mean $\mathrm{PaO}_{2} / \mathrm{FIO}_{2}$ on admission in Group I was (131 \pm 3.3$)$ while in Group II was $(118 \pm 2.9)$ without any significant statistical difference. $(\mathrm{P}>0.05)$.
Also, mean SAPS II on admission in Group I \& II were $(41.7 \pm 3.89 \& 39.3 \pm 5.25)$ respectively without any significant statistical difference. $(\mathrm{P}>0.05)$.

(Table -4): Ventilatory parameters on days $1,3,7$ in the studied patients:

\begin{tabular}{lccc}
\hline Parameter & Group I & Group II & P value \\
\hline VT ml/kg & Day 1 & & 0.000 \\
\hline FIo $_{2} \%$ & $5.7 \pm 0.57$ & $7.5 \pm 0.5$ & 0.066 \\
\hline P.Plateau Cm H2o & $66.5 \pm 6.3$ & $70.5 \pm 7$ & 0.000 \\
\hline PEEP Cm H2o & $26.55 \pm 1.6$ & $31.1 \pm 1.9$ & 0.35 \\
\hline & $11.1 \pm 1.5$ & $10.5 \pm 2.7$ & 0.000 \\
\hline VT ml/kg & Day 3 & & 0.003 \\
\hline FIo $\%$ & $6 \pm 0$ & $7.52 \pm 0.7$ & 0.000 \\
\hline P.Plateau Cm H2o & $61.7 \pm 6.9$ & $68.8 \pm 6.5$ & 0.3 \\
\hline PEEP Cm H2o & $25.7 \pm 2.14$ & $32.76 \pm 4.1$ & 0.000 \\
\hline & $10.44 \pm 1.2$ & $9.94 \pm 1.71$ & 0.04 \\
\hline VT ml/kg & Day 7 & & 0.000 \\
\hline FIo $\%$ & $6 \pm 0$ & $7.3 \pm 0.48$ & 0.1 \\
\hline P.Plateau Cm H2o & $55.9 \pm 11.5$ & $66 \pm 11.25$ & \\
\hline PEEP Cm H2o & $24.6 \pm 4$ & $31.9 \pm 3.25$ & $10.9 \pm 2.07$ \\
\hline
\end{tabular}


This table shows the mean ventilatory parameters of both groups on the day1, 3,7.On day 1: VT was $5.7 \pm 0.57 \mathrm{ml} / \mathrm{kg}$ in Group I \& $7.5 \pm 0.5 \mathrm{ml} / \mathrm{Kg}$ in Group II with highly statistical significant difference. $(\mathrm{P}<0.05)$. $\mathrm{FIO}_{2}$ was $66.5 \pm 6.3 \% \& 70.5$ $\pm 7 \%$ in Group I \& II respectively but without any statistical significant difference. $(\mathrm{P}>0.05)$. $\mathrm{P}$ plateau was $26.55 \pm 1.6 \mathrm{CmH} 20 \& 31.1 \pm 1.9 \mathrm{CmH} 20$ in Group I \& II respectively with highly statistical significant difference. $(\mathrm{P}<0.05)$. PEEP was $11.1 \pm 1.5 \& 10.5 \mathrm{CmH} 20 \pm 2.7 \mathrm{CmH} 20$ in Group I \& II respectively but without any statistical significant difference. $(\mathrm{P}>0.05)$. On day 3: VT was $6 \pm 0$ in Group I \& $7.52 \pm 0.7$ in Group II with highly significant statistical difference. $(\mathrm{P}<0.05)$. $\mathrm{FIO}_{2}$ was $61.7 \pm 6.9 \& 68.8 \pm 6.5$ in Group I \& II respectively highly significant statistical difference.
$(\mathrm{P}<0.05)$. $\mathrm{P}$ plateau was $25.7 \pm 2.14 \& 32.7 \pm 4.1$ in Group I \& II respectively with highly significant statistical difference. $(\mathrm{P}<0.05)$. PEEP was 10.44 $\pm 1.29 \& 9.94 \pm 1.71$ in Group I \& II respectively but without any significant statistical difference. $(\mathrm{P}>$ $0.05)$. On day 7: VT was $6 \pm 0$ in Group I \& $7.3 \pm$ 0.48 in Group II with highly statistical significant difference. $(\mathrm{P}<0.05)$. $\mathrm{FIO}_{2}$ was $55.9 \pm 11.5$ vs. $66 \pm$ 11.25 in Group I \& II respectively with significant statistical difference. $(\mathrm{P}>0.05)$.

P plateau was $24.6 \pm 4$ vs. $31.9 \pm 3.25$ in Group I \& II respectively with highly statistical significant difference. $(\mathrm{P}<0.05)$. PEEP was $9.5 \pm 2.4$ vs. 10.9 \pm 20.7 in Group I \& II respectively but without any significant statistical difference. $(\mathrm{P}>0.05)$.

(Table -5): Arterial blood gases on day 1,3,7 in the studied patients:

\begin{tabular}{|c|c|c|c|}
\hline Day 1 & Group I & Group II & $P$ value \\
\hline $\mathrm{PH}$ & $7.35 \pm 0.03$ & $7.34 \pm 0.02$ & 0.12 \\
\hline $\mathrm{PaCo} 2 \mathrm{mmHg}$ & $39.4 \pm 3.2$ & $39.3 \pm 1.9$ & 0.85 \\
\hline $\mathrm{PaO} 2 \mathrm{mmHg}$ & $64.9 \pm 3.9$ & $69.45 \pm 7.2$ & 0.019 \\
\hline Day 3 & Group I(18) & Group II(17) & $\overline{P \text { value }}$ \\
\hline $\mathrm{PH}$ & $7.39 \pm 0.026$ & $7.36 \pm 0.03$ & 0.02 \\
\hline$\overline{\mathrm{PaCO}_{2}}$ & $40.5 \pm 2.38$ & $40.4 \pm 1.9$ & 0.9 \\
\hline$\overline{\mathrm{PaO}_{2}}$ & $66.38 \pm 5.38$ & $67.47 \pm 6.6$ & 0.5 \\
\hline Day 7 & Group I(16) & Group II(10) & $\overline{P \text { value }}$ \\
\hline$\overline{\mathrm{PH}}$ & $7.39 \pm 0.003$ & $7.37 \pm 0.03$ & 0.02 \\
\hline $\mathrm{PaCO}_{2}$ & $42 \pm 2.5$ & $41.3 \pm 1.9$ & 0.4 \\
\hline$\overline{\mathrm{PaO}_{2}}$ & $68.12 \pm 2.5$ & $66 \pm 4.6$ & 0.1 \\
\hline
\end{tabular}

This table shows the difference between the values of (PH \& Paco2 \& Pao2) between both groups on day $1,3,7$.

On day 1 ( $\mathrm{PH} \& \mathrm{Paco} 2 \& \mathrm{Pao} 2)$ were $(7.35 \pm 0.03 \&$ $7.34 \pm 0.02) \&(39.4 \pm 3.2 \mathrm{mmHg} \& 39.3 \pm 1.9$ $\mathrm{mmHg}) \&(64.9 \pm 3.9 \mathrm{mmHg} \& 69.45 \pm 7.2 \mathrm{mmHg}$ ) respectively but with only significant statistical difference in Pao2.$(\mathrm{P}<0.05)$.

On day 3 (PH \& Paco2 \& Pao2) were $(7.39 \pm 0.026$ $\& 7.36 \pm 0.03)$ with significant statistical difference.
$(\mathrm{P}<0.05) . \&(40.5 \pm 2.38 \& 40.4 \pm 1.9) \&(66.38 \pm$ $5.38 \& 67.47 \pm 6.6)$ respectively but without any significant statistical difference. $(\mathrm{P}>0.05)$.

On day 7 (PH \& Paco2 \& Pao2) were $(7.39 \pm 0.03$ vs. $7.37 \pm 0.03)$ with significant statistical difference. $(\mathrm{P}<0.05) . \&(42 \pm 2.5$ vs. $41.3 \pm 1.9)$ $\&(68.12 \pm 2.5$ vs. 66.46$)$ respectively but without any significant statistical difference. $(\mathrm{P}>0.05)$. 
(Table-6): The outcome of studied groups in relation to mortality

\begin{tabular}{llll}
\hline Outcome & Survived & Died & P value \\
\hline Group I (20) n (\%) & $8(40 \%)$ & $12(60 \%)$ & 0.028 \\
\cline { 1 - 3 } Group II (20) n (\%) & $2(10 \%)$ & $18(90 \%)$ & \\
\hline
\end{tabular}

This table shows the percentage of survivors and survived and $60 \%$ died while $10 \%$ survived in deaths in both groups in which $40 \%$ of Group I Group II and $90 \%$ died with significant statistical difference $(\mathrm{p}<0.05)$.

(Table-7): duration of mechanical Ventilation in survivors

\begin{tabular}{llll}
\hline Survivor & Group I(8) & Group II(2) & P value \\
\hline Days on MV(S) & $18.6 \pm 1.7$ & $25.5 \pm 2.1$ & 0.001 \\
\hline
\end{tabular}

In survivors the mean duration of mechanical ventilation was 18.6 \pm 1.7 days in Group I and

$25.5 \pm 2.1$ days in Group II with significant statistical difference $\mathrm{p}<0.05$

(Table-8): Length of stay (LOS) in ICU in survivor

\begin{tabular}{llll}
\hline survivor & Group I(8) & Group II(2) & P value \\
\hline LOS in ICU & $22.6 \pm 1.6$ & $30.5 \pm 3.5$ & 0.001 \\
\hline
\end{tabular}

This table shows that LOS in survivors in Group I and II was $(22.6 \pm 1.6,30.5 \pm 3.5)$ respectively with significant statistical difference $(<0.05)$.

(Table -9): frequency of complications in the studied group

\begin{tabular}{lccc}
\hline Complication & $\begin{array}{c}\text { Group } \\
\text { I (20) }\end{array}$ & Group II(20) & P \\
\hline $\begin{array}{l}\text { Acute renal } \\
\text { failure }\end{array}$ & $25 \%$ & $20 \%$ & 1 \\
\hline VAP & $15 \%$ & $15 \%$ & 1 \\
\hline Pneumothorax & $5 \%$ & $30 \%$ & .037 \\
\hline Arrhythmia & $15 \%$ & $35 \%$ & 0.14 \\
\hline Bed sores & $20 \%$ & $5 \%$ & 0.15 \\
\hline $\begin{array}{l}\text { Upper GIT } \\
\text { bleeding }\end{array}$ & $10 \%$ & $10 \%$ & 1 \\
\hline
\end{tabular}


This table shows the frequency of complications in the studied population in which acute renal failure was the most frequent complication in Group I (25\% ) compared to (20\%) in Group II. arrhythmia was the most frequent complication in Group II $35 \%$ compared to $15 \%$ in Group I .other complications in Group I and II were VAP $(15 \%$, $15 \%)$,bed sores $(20 \%, 5 \%)$ upper GIT bleeding $(10 \%, 10)$ respectively.

Regarding pneumothorax frequency in Group I \& II was (5\%-30\%) respectively with significant statistical difference.

\section{DISCUSSION}

As regard the etiology of ALI/ARDS (table 2 ), the most frequent etiology in both groups were sepsis (30\% in group I) and pneumonia (30\% in group II) without any significant statistical difference between the 2 groups, in agreement with (Stewart et al.,1998) ${ }^{[8]}$ and (Kallet et al., 2005) ${ }^{[9]}$.

Other etiologies in group I and II include: aspiration (10\% vs. $10 \%)$, trauma (25\% vs. $20 \%)$, H1N1 (0\% vs. $15 \%)$, drug overdose (10\% vs. $0 \%)$ respectively in both groups (table 2 ).

In group II there were 3 cases of ARDS caused by $\mathrm{H} 1 \mathrm{~N} 1$ at the period from second half of 2009 and 2010 but in group I there were no cases of H1N1.

In March 2009 a novel influenza virus emerged in Mexico and the United States and quickly spread worldwide. The pandemic A (H1N1) virus originated from the triple-reassortment of swine influenza (H1) virus circulating in North American pigs. On June 11, 2009, WHO declared a world pandemic alert. By August 1, 2010, almost every country had reported laboratory-confirmed cases, with over 18,449 deaths. (Hendrickson and Matthay , 2013) ${ }^{[2]}$.

The majority of H1N1-infected patients were children or adults aged $<60$ years; most recovered uneventfully, and the overall mortality was not higher than that of seasonal influenza. Risk factors for more severe infection by pandemic H1N1 include extremes of age, underlying medical illness, obesity, and pregnancy. However, some previously healthy patients without co-morbidities developed rapidly progressive pneumonia, ARDS, multi-organ failure, and death. (Louie et al, 2010) ${ }^{[10]}$.

As regards $\mathrm{PaO}_{2} / \mathrm{FIo}_{2}$ ratio and SAPS II score at admission (table 3) there was no significant statistical difference between group I and II, $\mathrm{PaO}_{2} / \mathrm{FIo}_{2}(131 \pm 33$ vs. $118 \pm 20)$ and SAPS II
$(41.7 \pm 3.89$ vs. $39.3 \pm 5.25)$ respectively and this was in harmony with Brochard et al. $(1998)^{[7]}$ and Kallet et al. (2005) ${ }^{[9]}$.

The SAPS II, based on a large international sample of patients, provides an estimate of the risk of death without having to specify a primary diagnosis (Le Gall et al., 1993) ${ }^{[4]}$.

$\mathbf{P a o}_{2} / \mathrm{FIo}_{2}$ ratio was used by $\mathrm{AECC}$ definition of ARDS to discriminate between ALI and ARDS (ALI non-ARDS $(200 \mathrm{~mm}$ $\mathrm{Hg}<$ Pao2/FIo2 $\leq 300 \mathrm{~mm} \mathrm{Hg}$ ) and ARDS alone (Pao2/FIo2 $\leq 200 \mathrm{~mm} \mathrm{Hg}$ ) (Bernard et al., 1994) ${ }^{[12]}$.

The Berlin definition of acute respiratory distress syndrome used Pao2/FIo2 ratio with PEEP or $\mathrm{CPAP} \geq 5 \mathrm{~cm} \mathrm{H} 2 \mathrm{O}$ to classify ARDS into 3 categories according to severity and consequently its impact on the outcome $(200<$ Pao2/FIo $2 \leq 300$, $100<$ Pao2/FIo2 $\leq 200$, and Pao2/FIo2 $\leq 100$ ) for (mild, moderate, and severe ARDS ) respectively (Ferguson et al.,2012) $^{[13]}$.

By monitoring the venilatory parameters in group I and II in this study on days 1, 3, 7 in (table 4) respectively; there was a very significant statistical difference regarding tidal volume $(5.7 \pm 0.57$ vs. $7.5 \pm 0.5)$ on day $1,(6 \pm 0$ vs. $7.52 \pm 0.7)$ on day 3 , and $(\mathbf{6} \pm \mathbf{0}$ vs. $\mathbf{7 . 3} \pm \mathbf{0 . 4 8})$ on day 7 respectively.

The use of this tidal volume was reflected on the plateau pressure as follows $(\mathbf{2 6 . 5 5} \pm \mathbf{1 . 6}$ vs. 31.1 \pm 1.9$)$ on day $1,(25.7 \pm 2.14$ vs. $32.76 \pm 4.1)$ on day 3 , and (24.6 \pm 4 vs.31.9 \pm 3.25$)$ on day 7 ; with a very significant statistical difference between the two groups.

This was in harmony with (Kallet et al., 2005) $)^{[9]}$ and (Villar et al., 2006) ${ }^{[14]}$.

However in this study with complete application of ARDS Network ventilatory protocol a lower $\mathrm{FIo}_{2}$ in group I on day 3 was reached which continued till the end of the study with a significant statistical difference despite of non-significant statistical difference in PEEP and $\mathrm{PaO}_{2}$ between the two groups.

This was in contrary to Kallet et al. $(2005)^{[9]}$ in which there was a highly significant difference in PEEP between the studied groups on day 1.

Also at Villar et al. (2006) ${ }^{[14]}$ study there was also a high significant difference in PEEP between the studied groups all over the study.

This can be explained by the relative lower tidal volume in this study compared to the 
aforementioned studies where the PEEP difference may affect $\mathrm{FIo}_{2}$.

In one uncontrolled study of 53 patients with severe ARDS, the hospital mortality rate was significantly lower than that predicted by the Acute Physiology and Chronic Health Evaluation II scores (26.4\% vs. 53.3\%, $p=.004)$ (Hickling et al., 1994) ${ }^{[15]}$.

Several uncontrolled trials confirm that the technique of permissive hypercapnia is safe and leads to reasonable outcomes (Gentilello et al., 1995) ${ }^{[16]}$.

At 1990 Lee et al. ${ }^{[17]}$ conducted One randomized study of low tidal volume $(\mathrm{VT}=6$ $\mathrm{mL} / \mathrm{kg}$ ) vs. what was considered standard tidal volume (VT $=12 \mathrm{~mL} / \mathrm{kg})$ in all ventilated patients in a surgical intensive care unit (ICU); found decreased morbidity in the low tidal volume group; The incidence of pulmonary infection tended to be lower and duration of intubation and hospital stay tended to be shorter for non-neurosurgical and noncardiac surgical patients randomized to low VT. The use of low VT was associated with a statistically significant but clinically irrelevant decrease in oxygenation.

Another four multicenter studies have compared limited volume and pressure ventilation (VT , $8 \mathrm{~mL} / \mathrm{kg}$ or peak inspiratory pressure, $30 \mathrm{~cm}$ $\mathrm{H} 2 \mathrm{O})$ to a strategy with what was considered conventional ventilation (VT of $10-15 \mathrm{~mL} / \mathrm{kg}$ or peak inspiratory pressure ,50 cm H2O) (Brochard et al., $1998^{[11]}$, Stewart et al., $1998^{[8]}$, and Ranieri et al., 1999 ${ }^{[18]}$.

In the study of Stewart et al. $(\mathbf{1 9 9 8})^{[8]}, 120$ patients at high risk for ARDS had a mortality of $50 \%$ in the limited- ventilation group and $47 \%$ in the control group without any significant statistical difference.

In the study of Brochard et al. $(1998)^{[11]}$, a total of 116 patients with ARDS and no organ failure other than the lung were enrolled in 25 centers. Mortality at day 60 (low VT $46.6 \%$ vs. control $37.9 \%, p=0.38$ ), duration of mechanical ventilation (23.1 vs. 21.4 days, $\mathrm{p}=0.85)$, the prevalence of pneumothorax $(14 \%$ vs. $12 \%$, p $=0.78$ ).

An alternative lung protective ventilation strategy is the "open lung" technique conducted by Amato et al. $\left(\mathbf{1 9 9 8}^{[19]}\right)$. This technique aimed to maintain a level of positive end-expiratory pressure above the level at which alveoli collapse, clinically defined as the "inflection point" in a lung pressure- volume curve, and limiting distending pressure and volume. A total

of 53 patients with ARDS were randomized to receive conventional or protective mechanical ventilation. Protective ventilation involved endexpiratory pressures above the lower inflection point on the static pressure-volume curve, a tidal volume of $<6 \mathrm{~mL}$ per kilogram, driving pressures of $<20 \mathrm{~cm}$ of water above the positive endexpiratory pressure value, permissive hypercapnia, and preferential use of pressure-limited ventilator modes. In the protective-ventilation group, the 28day mortality was $38 \%$ as compared with $71 \%$ in the conventional-ventilation group $(\mathbf{p}=\mathbf{0 . 0 0 1})$.

However, the most definitive support for low volume/pressure ventilation has come from the National Institutes of Health (NIH) ARDS Network trial comparing $6 \mathrm{~mL} / \mathrm{kg}$ vs. $12 \mathrm{~mL} / \mathrm{kg}$ VT in patients with ALI and ARDS (ARMA, 2000) ${ }^{[20]}$ The NIH ARDS Network is a clinical trial consortium of 10 clinical centers including 24 hospitals.The Data Safety and Monitoring Board stopped the trial early after a planned data analysis. There were 432 patients enrolled into the $6 \mathrm{~mL} / \mathrm{kg}$ arm and 429 into the $12 \mathrm{~mL} / \mathrm{kg}$ group. Mean tidal volume in the lower stretch group was $6.2 \pm 0.8 \mathrm{~mL}$ vs. $11.8 \pm 0.8 \mathrm{~mL}$ in the traditional group. Mean end-expiratory plateau pressures were $25 \pm 6$ and 33 $\pm 8 \mathrm{~cm} \mathrm{H} 2 \mathrm{O}$, and the mortality before discharge in the two arms was $31.3 \%$ and $39.8 \%$ respectively (p $=0.01$ )

In this study there was an evidence that the adherence to ARDS Network ventilatory protocol with the low tidal volume based on predicted body weight and guarding against high plateau pressure was associated with a decrease in the overall mortality from $90 \%$ in the retrospective group to $60 \%$ in the intervention group with a significant statistical difference ( $p$ value: 0.028$)$, and this reduction in mortality was independent of age , SAPS II , pH, $\mathrm{PaO}_{2} / \mathrm{FI}_{\mathrm{O} 2}$, other indices of disease severity, and the etiology of ALI/ARDS.

Although there is a mortality benefit in the intervention group it was noticed that the mortality in both groups is higher than in the aforementioned studies and other studies as Villar et al. (2006) ${ }^{[14]}$, and this can be explained by the previously limited resources in locality and the lack of respiratory therapists, and also the very low nurse/bed ratio and possibly the differences in the etiology of ARDS patients ( 3 cases $\mathrm{H} 1 \mathrm{~N} 1)$. 
The ICU mortality in Villar et al. (2006) ${ }^{[14]}$ was $53.3 \%$ (24 of 45 ) in the control group vs. $32 \%$ (16 of 50) in the intervention group with a significant statistical difference ( $p$ value: 0.04 ), in the randomized controlled study that was done by Villar et al. a control group of established ARDS were ventilated using a tidal volume of $9-11 \mathrm{ml} / \mathrm{kg}$ of predicted body weight and a PEEP $\geq 5 \mathrm{~cm} \mathrm{H}_{2} \mathrm{O}$ and an intervention group that was ventilated using a tidal volume of $5-8 \mathrm{ml} / \mathrm{kg}$ predicted body weight and a PEEP that was set on day 1 to be above the lower inflection point of the pressure volume curve of the respiratory system.

In kallet et al. (2005) ${ }^{[9]}$ which was a retrospective uncontrolled study the patients managed with ARDS Network protocol had a lower hospital mortality compared with historical controls (32\% vs. $51 \%$, respectively; $p=0.004)$

As regard the percentage of survivor and deaths at specific day intervals (table 6) ; In the first three days ,90\% survival and $10 \%$ died in group I , while $85 \%$ survived and $15 \%$ died in group II with total deaths $12.5 \%$ in both groups from 3rd day to 7 th day ,80\% survived and $20 \%$ died in group I compared to $50 \%$ survived and $50 \%$ died in group II with total deaths $35 \%$ in both groups after the 7th day till the end of the study at $40 \%$ survived and $60 \%$ died in group I while in group II $10 \%$ survived and $90 \%$ died with statistical significant difference $(\mathrm{p}<0.05)$ with total deaths , $75 \%$ in both groups. This was in consistence with kallet et al. $(2005)^{[9]}$ in which at the $1^{\text {st }} 3$ days there was $84 \%$ survived patients and $16 \%$ died patients in the lower tidal volume group, and $77 \%$ survived patients and $23 \%$ died ones in the higher tidal volume group with an overall mortality in both groups $19 \%$; by day 7 there was $60 \%$ survived patients and $40 \%$ died ones in the lower tidal volume group and $57.6 \%$ survived and $42.4 \%$ died in the control group with an overall mortality in both groups $41 \%$.

As regard duration of mechanical ventilation (table 7) In survivors the mean duration of mechanical ventilation was $18.6 \pm 1.7$ days in group I and $25.5 \pm 2.1$ days in group II with statistical significant difference $\mathrm{p}<0.05$ this was in agreement with Amato et al. (1998) $)^{[19]}$ in which the duration of mechanical ventilation was expressed as weaning from mechanical ventilation at day 28 which was 19 cases of 29 ones $(66 \%)$ in the lower tidal volume group vs. 7 cases of 24 (29\%) in the higher tidal volume group with highly significant statistical difference $(\mathrm{p}=0.005)$.
This also was in harmony with $\boldsymbol{A R M A}$ trial (2000) ${ }^{[20]}$ in which in which the duration of mechanical ventilation was expressed as ventilatorfree days which was $12 \pm 11$ in the lower tidal volume group and $10 \pm 11$ in the control group with significant statistical difference $(\mathrm{p}=0.007)$.

This was also in consistence with Villar et al. (2006) $)^{[14]}$ in which the duration of mechanical ventilation was expressed as ventilator-free days which was $10.9 \pm 9.4$ in the lower tidal volume group and $6.0 \pm 7.9$ in the control group with significant statistical difference $(\mathrm{p}=0.008)$

As regard length of stay in ICU (table 8) LOS in survivors in group I and II was $(22.6 \pm 1.6$ vs. $30.5 \pm 3.5)$ respectively with significant statistical difference $(\mathrm{p}<0.05)$.

This was not in consistence with Stewart et al. $\left(1998^{[8]}\right)$ in which the lenghth of stay in ICU was more in the limited tidal volume group than in the controlled group $(19.9 \pm 39$ vs. 13.7 \pm 15.8$)$ respectively with no significant statistical difference $(\mathrm{p}<0.05)$.

The lenghth of stay in ICU was also more in the limited tidal volume group than in the controlled group also in Brochard et al. $\left(\mathbf{1 9 9 8}^{[11]}\right)(33.5 \pm 28.7$ vs. $29.7 \pm 19.4$ ) with no significant statistical difference between the two groups.

This can be explained by the difference in defining ARDS patients in their studies, and also we used a much lower tidal volume in this study in group I which was less than $6 \mathrm{ml}$ of predicted body weight; but in both Brochard et al. $\left(1998^{[11]}\right)$ and Stewart et al. $(1998)^{[8]}$ the tidal volume was more than $7 \mathrm{ml}$ per kilogram and was not based on predicted body weight

As regard frequency of complications in the studied group( table 9) the frequency of complications in the studied population in which acute renal failure was the most frequent complication in group I (25\%) compared to (20\%) in group II. arrhythmia was the most frequent complication in group II $35 \%$ compared to $15 \%$ in group I .other complications in group I and II were VAP $(15 \%, 15 \%)$, bed sores $(20 \%, 5 \%)$ upper GIT bleeding $(10 \%, 10)$ respectively without any significant statistical difference .But regarding pneumothorax frequency in group I \& II was $(5 \%$ $30 \%$ ) respectively with significant statistical difference and this was in consistence with Villar $\boldsymbol{e t}$ al. $(2006)^{[14]}$.

Conclusions: Application of ARDS Network ventilatory protocol as a ventilatory strategy in 
ARDS patients decreases the overall mortality, days on mechanical ventilation, the length of stay in ICU and the incidence of barotrauma.

\section{REFERENCES}

1. Dechert R. E., Carl F. Haas C. F., and Ostwani W. (2012): Current Knowledge of Acute Lung Injury and Acute Respiratory Distress Syndrome. Crit Care Nurs Clin N Am; 24: 377-401.

2. Hendrickson C. M. and Matthay M. A. (2013): Viral Pathogens and Acute Lung Injury: Investigations Inspired by the SARS Epidemic and the 2009 H1N1 Influenza Pandemic Semin Respir Crit Care Med; 34:475-486.

3. Girard T. D. and Bernard G. R. (2007): Mechanical Ventilation in ARDS: A Stateof-the-Art Review. Chest; 131: 921-929.

4. Le Gall JR., Lemeshow S., Saulnier F. (1993): A New Simplified Acute Physiology Score (SAPS II) Based on a European/North American Multicenter Study. JAMA. 1993; 270:2957-2963.

5. Thompson T. and Bernard G.R.(2011): ARDS Network(NHLBI) Studies:Successes andChallenges in ARDS Clinical Research Crit Care Clin 27 (2011) 459468.

6. Meade M. O., Cook D. J., Guyatt G. H. et al.(2008): Ventilation Strategy Using Low Tidal Volumes, Recruitment Maneuvers, and High Positive End Expiratory Pressure for Acute Lung Injury and Acute Respiratory Distress Syndrome A Randomized Controlled Trial JAMA ;299(6):637-645

7. Brochard, L.; Roudot-Thoraval, F. et al. (1998): Tidal volume reduction for prevention of ventilator-induced lung injury in acute respiratory distress syndrome. The multicenter trial group on tidal volume reduction in ARDS. Am $\mathrm{J}$ Respir Crit Care Med; 158: 1831-8.

8. Stewart, T.E.; Meade, M.O. and Cook, D.J. et al. (1998): Evaluation of a ventilation strategy to prevent barotrauma in patients at high risk of acute respiratory distress syndrome. N Engl J Med; 338: 355-61.
9. Kallet R. H., Jasmer R. M., Pittet JF, et al. (2005): Clinical implementation of the ARDS network protocol is associated with reduced hospital mortality compared with historical controls Crit Care Med ; Vol. 33, No. 5 : 926-929.

10. Louie J.K., Acosta M., Jamieson D.J., Honein M.A. (2010): California Pandemic (H1N1) Working Group. Severe 2009 H1N1 influenza in pregnant and postpartum women in California. N Engl J Med;362(1):27-35.

11. Brochard, L.; Roudot-Thoraval, F. et al. (1998): Tidal volume reduction for prevention of ventilator-induced lung injury in acute respiratory distress syndrome. The multicenter trial group on tidal volume reduction in ARDS. Am J Respir Crit Care Med; 158: 1831-8.

12. Bernard, G.; Artigas, A. and Brigham, K. et al. (1994): The American-European Consensus Conference on ARDS: Definitions, mechanisms, relevant outcomes, and clinical trial coordination. Am J Respir Crit Care Med; 149(3): 81824.

13. Ferguson N.D., Fan E., Camporota L., et al. (2012): The Berlin Definition of ARDS: An Expanded Rationale, Justification, and Supplementary Material. Intensive Care Med.;38(10):1731-1732

14. Villar J., Kacmarek R. M., Pérez-Méndez L., et al. (2006): A high positive endexpiratory pressure, low tidal volume ventilatory strategy improves outcome in persistent acute respiratory distress syndrome: A randomized, controlled trial Crit Care Med Vol. 34, No. 5:1311-1318.

15. Hickling K.G., Henderson S.J., and Jackson R. (1990): Low mortality associated with low volume pressure limited ventilation with permissive hypercapnia in severe adult respiratory distress syndrome. Intensive Care Med; 16:372-377)

16. Gentilello L.M., Anardi D., Mock C., et al. (1995): Permissive hypercapnia in trauma patients. J Trauma; 39:846-852. 
17. Lee P.C., Helsmoortel C.M., Cohn S.M., et al. (1990): Are low tidal volumes safe? Chest; 97:430-434.

18. Ranieri V.M., Suter P.M., Tortorella C., et al. (1999): Effect of mechanical ventilation on inflammatory inflammatory mediators in patients with acute respiratory distress syndrome: A randomized controlled trial. JAMA; 282:54-61

19. Amato, M.; Barbas, C. and Medeiros, D. et al. (1998): Effect of a protective-ventilation strategy on mortality in the acute respiratory distress syndrome. $\mathrm{N}$ Engl $\mathrm{J}$ Med; 338(6): 347-54.

20. Acute Respiratory Distress Syndrome Network, (2000): Ventilation with lower tidal volumes as compared with traditional tidal volumes for acute lung injury and the acute respiratory distress syndrome. N Engl J Med; 342(18):1301-8. 